\title{
Risk of chronic obstructive pulmonary disease in
} healthy individuals with high C-reactive protein levels by smoking status: a population-based cohort study in Korea

\author{
Seong Yong Lim ${ }^{1, *}$ \\ Di Zhao ${ }^{2, *}$ \\ Eliseo Guallar ${ }^{2}$ \\ Yoosoo Chang ${ }^{3}$ \\ Seungho Ryu ${ }^{3}$ \\ Juhee $\mathrm{Cho}^{4}$ \\ Jung Yeon Shim ${ }^{5}$ \\ 'Division of Pulmonary and Critical Care \\ Medicine, Department of Medicine, \\ Kangbuk Samsung Hospital, \\ Sungkyunkwan University School of \\ Medicine, Seoul, South Korea; \\ ${ }^{2}$ Department of Epidemiology and \\ Medicine, Welch Center for Prevention, \\ Epidemiology, and Clinical Research, \\ Johns Hopkins University Bloomberg \\ School of Public Health, Baltimore, MD, \\ USA; ${ }^{3}$ Department of Occupational and \\ Environmental Medicine, Kangbuk \\ Samsung Hospital, Sungkyunkwan \\ University, School of Medicine, Seoul, \\ South Korea; ${ }^{4}$ Department of Clinical \\ Research Design and Evaluation, SAIHST, \\ Sungkyunkwan University, Seoul, South \\ Korea; ${ }^{5}$ Department of Pediatrics, \\ Kangbuk Samsung Hospital, \\ Sungkyunkwan University School of \\ Medicine, Seoul, South Korea \\ *These authors contributed equally to \\ this work
}

Correspondence: Jung Yeon Shim Department of Pediatrics, Kangbuk Samsung Hospital, Sungkyunkwan

University School of Medicine, 29

Saemunanro, Jongro-ku, Seoul 03I8I,

South Korea

Tel +82220012200

Fax +82220011922

Email jy7.shim@samsung.com
This article was published in the following Dove Press journal:

International Journal of Chronic Obstructive Pulmonary Disease

\begin{abstract}
Purpose: Chronic obstructive pulmonary disease (COPD) is associated with systemic inflammation. We investigated whether elevated baseline serum C-reactive protein (CRP) levels in healthy individuals are associated with the risk of incident COPD by smoking status.

Patients and methods: This was a cohort study of 63,260 adult men and women who were older than 40 years, free of COPD at baseline, and underwent health screening from 2002 to 2016 with at least one follow-up visit through December 2016. We investigated the association between baseline high-sensitivity CRP (hsCRP) levels and incident COPD by smoking status, using flexible parametric proportional hazards models and pooled logistic regression analyses.
\end{abstract}

Results: The multivariable-adjusted hazard ratio ( $95 \%$ confidence interval) comparing participants in the 90th to those in the 10th percentile of hsCRP was $1.19(1.08,1.31)$ The corresponding hazard ratio in never, former, and current smokers were $1.07(0.89,1.29)$, $1.22(1.05,1.42)$, and $1.22(1.05,1.41)$, respectively. The association between hsCRP levels and incident COPD had a similar dose-response pattern in former and current smokers, but not in never smokers.

Conclusion: Higher baseline hsCRP is associated with an increased risk to develop COPD in ever smokers but not in never smokers.

Keywords: smokers, C-reactive protein, systemic inflammation, COPD, cohort studies

\section{Introduction}

Chronic obstructive pulmonary disease (COPD) is an inflammatory disorder characterized by persistent airflow limitation, affecting approximately $10 \%$ of adults over 40 years of age. ${ }^{1}$ The World Health Organization projects that COPD will become the third leading cause of death worldwide by $2030 .^{2}$ Local pulmonary inflammation, which is characterized by an abnormal inflammatory response induced by a variety of cytokines and activated inflammatory cells in response to cigarette smoke and other environmental pollutants in a susceptible host, is a hallmark of COPD. ${ }^{3}$

An increasing body of evidence indicates that COPD is associated with systemic inflammation, in addition to local pulmonary inflammation. ${ }^{4,5}$ Indeed, systemic inflammatory biomarkers such as C-reactive protein (CRP), circulating leukocytes, 
interleukin-6, interleukin-8, fibrinogen, and tumor necrosis factor- $\alpha$, are elevated in patients with COPD compared with subjects without COPD; ${ }^{6-10}$ furthermore, CRP is a predictor of prognosis in patients with COPD. ${ }^{11}$ The association between CRP levels and lung function, however, is not well characterized. Several investigators have reported an inverse cross-sectional relationship between CRP levels and lung function ${ }^{12,13}$ as well as an association between CRP levels and a higher likelihood of a clinical diagnosis of COPD. ${ }^{14,15}$ In contrast, several studies have reported negative or no associations of CRP levels with lung function decline. ${ }^{16,17}$

Smoking, a single most important risk factor for COPD, can lead to systemic inflammation and subsequently reduce lung function. However, there has been controversy on whether systemic inflammation by itself after adjusting smoking status and other confounding factors could induce lower lung function and COPD. ${ }^{13,14}$

In the present study, we used data from a large cohort of apparently healthy middle-aged adults ( $\geq 40$ years old) free of COPD at baseline to examine the association between CRP levels and COPD development based on repeated spirometry measures over follow-up by smoking status.

\section{Methods}

\section{Study population}

The Kangbuk Samsung Health Study, a multicenter cohort study, involves adult men and women who underwent a comprehensive health examination at the clinics of the Total Healthcare Center of the Kangbuk Samsung Hospital in Seoul and Suwon, South Korea, between January 1, 2002, and December 31, 2016. ${ }^{18}$ The present analysis was restricted to participants with at least one follow-up visit between January 1, 2011, and December 31, 2016 ( $n=311,524$; Figure 1). We subsequently excluded participants younger than 40 years (to exclude patients with potential asthma, and onset age of COPD is usually $>40$ years old, $n=223,891)$; participants with a history of COPD $\quad(n=1,299), \quad$ asthma $\quad(n=1,023)$, tuberculosis $(n=5,071)$, lung cancer $(n=27)$, or lung surgery $(n=98)$; participants with serum high-sensitivity C-reactive protein (hsCRP) level $>5 \mathrm{mg} / \mathrm{L}(\mathrm{n}=2,979)$ since these values can result from acute infection or reflect short-term inflammatory responses; and participants with baseline forced expiratory volume in 1 second $\left(\mathrm{FEV}_{1}\right)$ /forced vital capacity (FVC) $<0.7(\mathrm{n}=2,160)$. We then excluded participants with missing
Adults who underwent comprehensive health check-up examination at the Kangbuk Samsung Hospital screening centers between Jan 2002 and Dec 2016 and had at least one follow-up visit $(\mathrm{N}=311,524)$

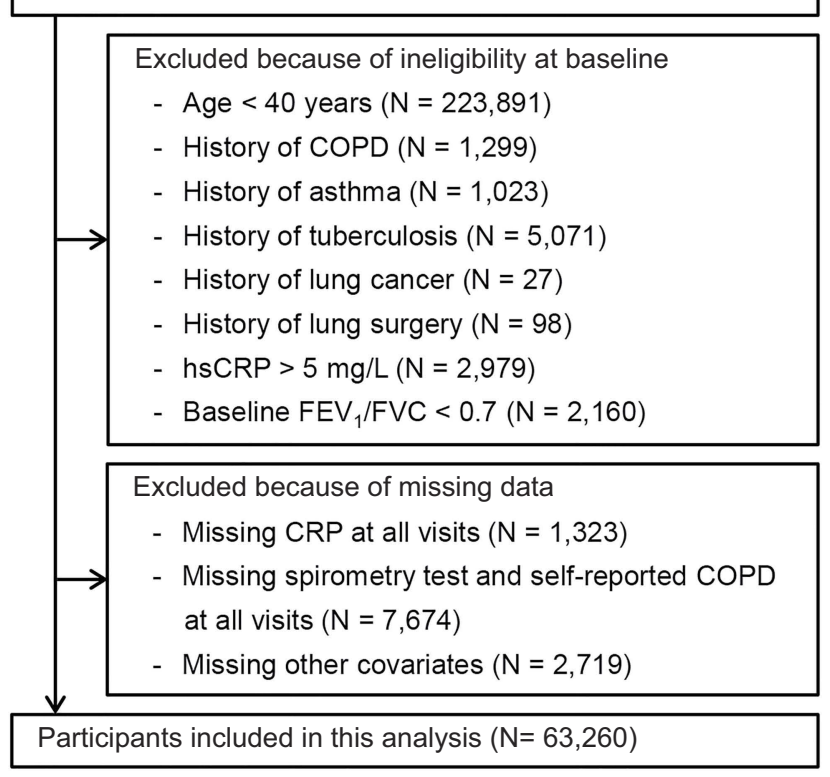

Figure I Flow chart of study design.

Abbreviations: COPD, chronic obstructive pulmonary disease; CRP, C-reactive protein; $\mathrm{FEV}_{\mathrm{l}}$, forced expiratory volume in I second; FVC, forced vital capacity; hsCRP, high-sensitivity C-reactive protein .

hsCRP measurements $(n=1,323)$, spirometry data and selfreported COPD status $(n=7,674)$, or other covariates $(n=2,719)$. The final study sample included 63,260 participants (38,843 men and 24,417 women).

The Institutional Ethics Committee of Kangbuk Samsung Hospital approved this study. The requirement of informed consent was waived as we only used deidentified data routinely collected during health screening visits.

\section{Data collection}

At each screening visit, we collected data on demographic characteristics, smoking status, alcohol consumption, physical activity, medical history, and medication use through standardized, self-administered questionnaires. The smoking status was categorized into never, former, or current smoker. Alcohol consumption was categorized into none, moderate ( $\leq 30$ grams/day in men and $\leq 20$ grams/day in women), or heavy ( $>30$ grams/day in men and $>20$ grams/ day in women). The frequency of vigorous physical activity was categorized into $0,1-3$, or $>3$ times/week.

Height, weight, and sitting blood pressure were measured by trained nurses. Body mass index was calculated 
as weight in kilograms divided by height in meters squared. Blood pressure was measured using an automated oscillometric device $(53,000$, Welch Allyn, NY, USA) in the sitting position with the arm supported at the heart level. Hypertension was defined as a systolic blood pressure of $\geq 140 \mathrm{mmHg}$, a diastolic blood pressure of $\geq 90 \mathrm{mmHg}$, or current use of antihypertensive medication.

Spirometry was performed as recommended by the American Thoracic Society, ${ }^{19}$ using Vmax 22 spirometers (SensorMedics, Yorba Linda, CA, USA). We used the highest $\mathrm{FVC}$ and $\mathrm{FEV}_{1}$ of three or more tests with acceptable curves, and COPD was defined as $\mathrm{FEV}_{1} / \mathrm{FVC}<0.7$ or self-reported COPD status. The forced vital capacity (FVC) is the amount of air that can be forcefully exhaled during the FVC maneuver, and the forced expiratory volume in one second $\left(\mathrm{FEV}_{1}\right)$ is the amount of air expelled during the first second. The ratio of $\mathrm{FEV}_{1}$ and $\mathrm{FVC}\left(\mathrm{FEV}_{1} /\right.$ FVC) is used as an indicator of airway obstruction.

We obtained blood samples after participants had fasted for at least $10 \mathrm{hrs}$. Serum hsCRP was measured with a particle-enhanced immunoturbidimetric assay on a Modular Analytics P800 apparatus (Roche Diagnostics, Tokyo, Japan). Serum total cholesterol and triglycerides were determined with an enzymatic colorimetric assay. High-density lipoprotein cholesterol was measured directly with a homogeneous enzymatic colorimetric assay. Diabetes was defined as a fasting serum glucose $\geq 126 \mathrm{mg} / \mathrm{dL}$, hemoglobin A1c $\geq 6.5 \%$, or current use of insulin or antidiabetic medications.

\section{Statistical analyses}

The study endpoint was development of incident COPD. Follow-up time was calculated from the baseline examination to COPD development or to the last health examination conducted for each participant, whichever occurred first. Because the exact time of COPD onset was unknown and it was between the visit for COPD diagnosis and the previous visit, we used flexible parametric proportional hazard models to account for this type of interval censoring. ${ }^{20}$ This survival model parameterized log cumulative hazards as natural cubic splines of log time with 3 internal knots at the 25th, 50th, and 75th percentiles. We estimated the hazard ratios for incident COPD comparing quintiles $2-5$ of the CRP level to the lowest quintile. In addition to categorical analysis, we modeled hsCRP as a continuous variable using restricted cubic splines (with knots at the 5th, 35th, 65th, and 95th percentiles of its sample distribution) to provide a flexible model for the dose-response relationship between hsCRP and COPD.

We used three models with increasing degrees of adjustment to account for potential confounding factors. The first model was adjusted for age (continuous), sex, and study center (Seoul or Suwon). The second model was further adjusted for smoking (never, former, or current), physical activity $(0,1-3$, or $>3$ times/week), alcohol consumption (none, moderate, or high), and body mass index (continuous). The third model was further adjusted for baseline $\mathrm{FEV}_{1}$ (continuous). The fourth model was further adjusted for hypertension (yes or no), total and high-density lipoprotein cholesterol (continuous), triglycerides (continuous), and fasting glucose (continuous).

In addition, interaction analyses were explored in prespecified subgroups defined by age ( $<50$ and $\geq 50$ years), sex, smoking, alcohol drinking, vigorous physical activity, body mass index $\left(<25\right.$ and $\left.\geq 25 \mathrm{~kg} / \mathrm{m}^{2}\right)$, hypertension, and diabetes. All reported $P$-values were two-sided, and the significance level was set at 0.05 . All analyses were performed using Stata version 15 (StataCorp LP, College Station, TX, USA).

\section{Results}

The average (standard deviation) age of the study participants was 46.8 (6.3) years. During 303,125 person-years of follow-up (mean follow-up: 4.9 years), 4,259 participants developed COPD. Current smokers were younger and had higher $\mathrm{FEV}_{1}$ and FVC than did never smokers at baseline but were more likely to develop COPD during follow-up (Table 1). Participants who developed COPD during follow-up were on average older and more likely to be male, alcohol drinkers, hypertensive, and physically active than those who did not develop COPD (Table S1).

The multivariable-adjusted hazard ratio (95\% confidence interval) for incident COPD comparing participants in the highest quintile of baseline hsCRP $(1.4-5 \mathrm{mg} / \mathrm{L})$ with those in the lowest quintile $(0.1-0.2 \mathrm{mg} / \mathrm{L})$ was 1.17 (1.06, 1.29; P trend <0.001; Table 2). The multivariableadjusted hazard ratio ( $95 \%$ confidence interval) comparing participants in the 90th to those in the 10th percentile of hsCRP was 1.19 (1.08, 1.31). The corresponding hazard ratios in never, former, and current smokers were 1.07 $(0.89,1.29), 1.22(1.05,1.42)$, and $1.22(1.05,1.41)$, respectively. However, adjusted hazard ratio comparing the 5 th to the 1 st quintile was most pronounced in the former smoker group (HR 1.22; 1.04-1.45), and less pronounced in the current smoker group (HR 1.14; 0.97-1.33). 
Table I Baseline characteristics of study participants by smoking status

\begin{tabular}{|c|c|c|c|c|c|}
\hline Characteristic & Overall & Never & Former & Current & $P$-value \\
\hline $\mathrm{N}$ & 63,260 & 28,989 & 18,392 & 15,879 & \\
\hline Age (years) & $46.8(6.3)$ & $47.0(6.6)$ & $47.3(6.6)$ & $45.6(5.3)$ & $<0.001$ \\
\hline C-reactive protein $(\mathrm{mg} / \mathrm{L})^{\mathrm{a}}$ & $0.5(0.2-1.0)$ & $0.4(0.2-0.9)$ & $0.5(0.2-1.0)$ & $0.6(0.3-1.2)$ & $<0.001$ \\
\hline $\mathrm{FEV}_{\mathrm{I}}$ & $3.3(0.8)$ & $2.9(0.7)$ & $3.6(0.7)$ & $3.6(0.7)$ & $<0.001$ \\
\hline FVC & $3.9(0.9)$ & $3.4(0.8)$ & $4.3(0.7)$ & $4.3(0.7)$ & $<0.001$ \\
\hline $\mathrm{FEV}_{\mathrm{l}} / \mathrm{FVC}$ & $84.2(6.6)$ & $85.0(6.3)$ & $83.8(6.6)$ & $83.4(6.7)$ & $<0.001$ \\
\hline COPD during follow-up & $4,259(6.7)$ & $\mathrm{I}, 025$ & $\mathrm{I}, 564(8.5)$ & $1,670(10.5)$ & $<0.001$ \\
\hline Male & $38,843(61.4)$ & $6,809(23.5)$ & I6,755 (91.I) & I5,279 (96.2) & $<0.001$ \\
\hline Study center & & & & & $<0.001$ \\
\hline Seoul & $50,962(80.6)$ & $23,299(80.4)$ & $14,948(8 \mid .3)$ & $12,715(80.1)$ & \\
\hline Suwon & $12,298(19.4)$ & $5,690(19.6)$ & $3,444(18.7)$ & $3,164(19.9)$ & \\
\hline Body mass index $\left(\mathrm{kg} / \mathrm{m}^{2}\right)$ & $23.9(2.9)$ & $23.2(3.0)$ & $24.5(2.7)$ & $24.6(2.8)$ & $<0.001$ \\
\hline Total cholesterol (mg/dL) & $201.7(34.7)$ & $198.3(34.2)$ & $204.0(34.8)$ & $205.0(35.1)$ & $<0.001$ \\
\hline HDL cholesterol (mg/dL) & $55.6(13.4)$ & $59.0(13.9)$ & $53.8(12.5)$ & $51.4(11.9)$ & $<0.001$ \\
\hline Triglycerides $(\mathrm{mg} / \mathrm{dL})^{\mathrm{a}}$ & $110.0(77.0-162.0)$ & $91.0(66.0-130.0)$ & $121.0(86.0-173.0)$ & $143.0(10 \mid .0-204.0)$ & $<0.001$ \\
\hline Alcohol & & & & & $<0.001$ \\
\hline None & $19,528(30.9)$ & $14,659(50.6)$ & $3,352(18.2)$ & $\mathrm{I}, 517(9.6)$ & \\
\hline Moderate & $34,949(55.2)$ & $13,128(45.3)$ & II,758 (63.9) & $10,063(63.4)$ & \\
\hline Severe & $8,783(13.9)$ & $\mathrm{I}, 202(4 . \mathrm{I})$ & $3,282(17.8)$ & $4,299(27.1)$ & \\
\hline Vigorous exercise (times/week) & & & & & $<0.001$ \\
\hline 0 & $30,974(49.0)$ & I5,547 (53.6) & $7,373(40.1)$ & $8,054(50.7)$ & \\
\hline $1-3$ & $21,47 \mid(33.9)$ & $8,188(28.2)$ & $7,370(40.1)$ & $5,913(37.2)$ & \\
\hline$>3$ & $10,815(17.1)$ & $5,254(\mid 8.1)$ & $3,649(19.8)$ & $1,912(12.0)$ & \\
\hline Fasting glucose (mg/dL) & $97.3(18.2)$ & $95.0(15.6)$ & $99.3(18.6)$ & $99.3(21.4)$ & $<0.001$ \\
\hline Diabetes & $3,795(6.0)$ & $1,206(4.2)$ & I,378 (7.5) & $1,211(7.6)$ & $<0.001$ \\
\hline Systolic blood pressure $(\mathrm{mmHg})$ & $114.8(14.6)$ & $112.4(15.2)$ & $117.8(14.1)$ & $115.8(13.4)$ & $<0.001$ \\
\hline Diastolic blood pressure $(\mathrm{mmHg})$ & $74.9(10.4)$ & $72.5(10.4)$ & $77.4(10.0)$ & $76.4(9.9)$ & $<0.001$ \\
\hline Hypertension & $13,915(22.0)$ & $5,089(17.6)$ & $5,247(28.5)$ & $3,579(22.5)$ & $<0.001$ \\
\hline
\end{tabular}

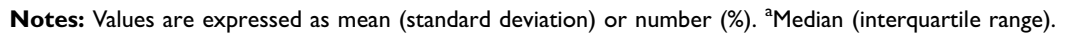

Abbreviations: COPD, chronic obstructive pulmonary disease; FEV , forced expiratory volume in I second; FVC, forced vital capacity; HDL, high-density lipoprotein.

The dose-response curve obtained using restricted cubic splines showed an increased risk of incident COPD with increasing hsCRP levels, although the increasing trend plateaued above hsCRP levels of $2 \mathrm{mg} / \mathrm{L}$ ( $P$-value for nonlinear spline terms $=0.002$; Figure $2 \mathrm{~A}$ ). The association between hsCRP levels and incident COPD had a similar dose-response pattern in former and current smokers (Figure 2B). In subgroup analyses, the risk of incident COPD increased with increasing hsCRP levels in all subgroups analyzed (Figure 3), except women, never smokers, non-drinkers, and participants with diabetes.

\section{Discussion}

In this large study of apparently healthy adult men and women over 40 years old, we found that high baseline hsCRP levels were significantly associated with an increased risk of COPD in ever smokers but not in never smokers, suggesting hsCRP can be regarded as a predictive marker, but not as an independent risk factor for developing COPD.

Several studies have demonstrated that patients with stable COPD have increased CRP levels compared with healthy controls, ${ }^{4,6,21}$ and that patients with severe COPD have higher serum CRP levels than those with moderate COPD. ${ }^{22}$ In prospective studies, however, the association of CRP levels with lung function decline is not yet conclusive. Rasmussen et al reported that a higher level of $\mathrm{CRP}$ at age 20 is associated with a greater reduction in $\mathrm{FEV}_{1}$ over nine years. ${ }^{23}$ The Coronary Artery Risk Development in Young Adults cohort study also showed that a higher year 7 CRP level was associated with greater loss of $\mathrm{FEV}_{1}$ and that, among participants with greater than 10 pack-years of cigarette exposure, year 7 CRP 
Table 2 Hazard ratios for incident COPD by time-varying CRP levels

\begin{tabular}{|c|c|c|c|c|c|c|}
\hline & $\begin{array}{l}\text { Log (CRP) (90th vs } \\
\text { I0th percentile) }\end{array}$ & $\begin{array}{l}\text { Ist Quintile } \\
(0.1-0.2 \mathrm{mg} / \mathrm{L})\end{array}$ & $\begin{array}{l}\text { 2nd Quintile } \\
(0.3 \mathrm{mg} / \mathrm{L})\end{array}$ & $\begin{array}{l}\text { 3rd Quintile } \\
(0.4-0.7 \mathrm{mg} / \mathrm{L})\end{array}$ & $\begin{array}{l}\text { 4th Quintile } \\
(0.8-1.3 \mathrm{mg} / \mathrm{L})\end{array}$ & $\begin{array}{l}\text { 5th Quintile } \\
\text { (1.4-5 mg/L) }\end{array}$ \\
\hline \multicolumn{7}{|l|}{ Overall } \\
\hline Incident rate ${ }^{\mathrm{a}}$ & 14.1 & 11.4 & 13.7 & 15.3 & 15.4 & 16.1 \\
\hline Model I & $1.31(1.20,1.43)$ & Reference (I) & $0.94(0.85,1.04)$ & $1.01(0.92,1.12)$ & $1.17(1.06,1.28)$ & $1.26(1.15,1.39)$ \\
\hline Model 2 & $1.23(1.12,1.35)$ & Reference (I) & $0.93(0.85,1.03)$ & $0.99(0.90,1.09)$ & $1.12(1.02,1.23)$ & $1.19(1.08,1.31)$ \\
\hline Model 3 & $1.14(1.04,1.25)$ & Reference (I) & $0.94(0.85,1.04)$ & $0.97(0.88,1.07)$ & $1.06(0.97,1.16)$ & $1.13(1.02,1.24)$ \\
\hline Model 4 & $1.19(1.08,1.31)$ & Reference (I) & $0.96(0.87,1.05)$ & $1.00(0.91,1.10)$ & $1.10(1.00,1.20)$ & I.I7 (1.06, I.29) \\
\hline \multicolumn{7}{|l|}{ Never smoker } \\
\hline Incident rate ${ }^{\mathrm{a}}$ & 8.0 & 7.1 & 8.2 & 7.9 & 8.5 & 9.4 \\
\hline Model I & $1.08(0.90,1.30)$ & Reference (I) & $1.04(0.87,1.25)$ & $0.99(0.82,1.20)$ & $1.05(0.87,1.26)$ & $1.08(0.88,1.32)$ \\
\hline Model 2 & $1.08(0.90,1.30)$ & Reference (I) & $1.05(0.88,1.26)$ & $1.00(0.83,1.22)$ & $1.05(0.87,1.27)$ & $1.08(0.88,1.33)$ \\
\hline Model 3 & $1.02(0.85,1.23)$ & Reference (I) & $1.06(0.88,1.27)$ & $0.98(0.81,1.19)$ & $1.00(0.82,1.20)$ & $\mathrm{I} .04(0.85, \mathrm{I} .28)$ \\
\hline Model 4 & $1.07(0.89,1.29)$ & Reference (I) & $1.09(0.91,1.30)$ & $1.03(0.85,1.25)$ & $1.04(0.86,1.26)$ & I. $10(0.89,1.35)$ \\
\hline \multicolumn{7}{|l|}{ Former smoker } \\
\hline Incident rate ${ }^{a}$ & 16.7 & 14.3 & 17 & 19.5 & 17.9 & 16.4 \\
\hline Model I & $1.29(1.11,1.49)$ & Reference (I) & $0.94(0.80,1.10)$ & $0.95(0.8 \mathrm{I}, \mathrm{I} . \mathrm{II})$ & $1.17(1.00,1.35)$ & $1.26(1.07,1.47)$ \\
\hline Model 2 & $1.29(1.11,1.49)$ & Reference (I) & $0.94(0.8 \mathrm{I}, \mathrm{I} . \mathrm{II})$ & $0.95(0.81,1.11)$ & $1.17(1.01,1.36)$ & $1.26(1.07,1.47)$ \\
\hline Model 3 & $1.20(1.03,1.39)$ & Reference (I) & $0.96(0.82,1.12)$ & $0.94(0.80,1.10)$ & I.II $(0.95,1.29)$ & $1.20(1.02,1.40)$ \\
\hline Model 4 & $1.22(1.05,1.42)$ & Reference (I) & $0.97(0.82,1.13)$ & $0.96(0.82,1.12)$ & I.I3 $(0.97,1.3 \mathrm{I})$ & $1.22(1.04,1.43)$ \\
\hline \multicolumn{7}{|l|}{ Current smoker } \\
\hline Incident rate $\mathrm{a}^{\mathrm{a}}$ & 21.2 & 18.7 & 20.3 & 21.5 & 21.4 & 23.6 \\
\hline Model I & $1.26(1.09,1.46)$ & Reference (I) & $0.84(0.71,1.00)$ & $1.02(0.87,1.19)$ & $1.10(0.95,1.28)$ & $1.16(1.00,1.35)$ \\
\hline Model 2 & $1.25(1.08,1.45)$ & Reference (I) & $0.85(0.72,1.00)$ & $1.02(0.88,1.20)$ & $1.10(0.95,1.28)$ & $1.15(0.99,1.34)$ \\
\hline Model 3 & I.I5 $(0.99,1.33)$ & Reference (I) & $0.84(0.7 \mathrm{I}, \mathrm{I} .00)$ & $0.98(0.84,1.15)$ & $1.03(0.88,1.19)$ & $1.08(0.92,1.25)$ \\
\hline Model 4 & $1.22(\mathrm{I} .05, \mathrm{I} .4 \mathrm{I})$ & Reference (I) & $0.86(0.73,1.02)$ & $1.02(0.87,1.19)$ & $1.07(0.92,1.25)$ & $1.14(0.97,1.33)$ \\
\hline
\end{tabular}

Notes: Hazard ratio derived from cox proportional hazard regression. Model I: Age (continuous), sex (man or woman), study center (Seoul or Suwon), and body mass index (continuous). Model 2: Additionally adjusted for smoking (never, former, current), physical activity ( 0 , I to 3, or $>3$ times/week), and alcohol consumption (none, moderate, high). Model 3: Additionally adjusted for baseline FEV (continuous). Model 4: Model 2+ hypertension (yes or no), total and high-density lipoprotein cholesterol (continuous), triglycerides (continuous), and fasting glucose (continuous). ${ }^{\mathrm{a}} \mathrm{Per} 1,000$ person-years.

Abbreviations: COPD, chronic obstructive pulmonary disease; CRP, C-reactive protein; FEV

levels were associated with greater odds of COPD. ${ }^{24}$ However, in a 16-year follow-up study in elderly subjects, baseline CRP levels failed to show a significant correlation with future lung function, whereas baseline fibrinogen levels showed an inverse correlation with future lung function. ${ }^{17}$

Conflicting information also exists regarding the association between serum CRP concentration and incident COPD, although available studies are somewhat limited. In our study, elevated baseline hsCRP levels were associated with incident COPD. This increased risk remained significant after adjustment for several confounders, including age, sex, smoking status, body mass index, diabetes mellitus, and concomitant cardiovascular disease, which are also associated with elevated CRP levels. ${ }^{25-27}$ Consistent with our results, hsCRP $>3 \mathrm{mg} / \mathrm{L}$ was associated with a significantly increased risk of incident
COPD compared with hsCRP $<1 \mathrm{mg} / \mathrm{L}$ among subjects aged 55 years or older in the population-based Rotterdam cohort study. ${ }^{14}$ However, Dahl et al found that, although elevated plasma CRP $>3 \mathrm{mg} / \mathrm{L}$ is related to both a diagnosis of COPD and subsequent hospital admission, elevated CRP is not genetically associated with an increased risk of COPD, suggesting that the association between CRP levels and COPD is not causal. ${ }^{15}$

Moreover, the mechanisms underlying systemic inflammation in patients with COPD are not clearly defined. There are two different theories on these mechanisms: first, the inflammatory process primarily originates in the airways and lung parenchyma and then "spills over" into the systemic circulation; ${ }^{28,29}$ second, similar to atherosclerosis and coronary artery disease, ${ }^{30} \mathrm{COPD}$ is the result of a systemic component that develops parallel to, or before, lung inflammation. ${ }^{28,31}$ In this study, CRP levels 
A

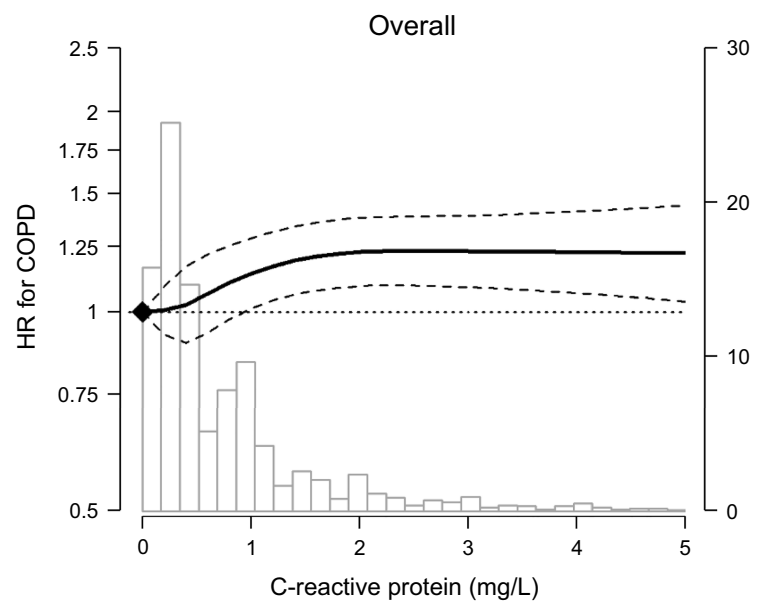

B

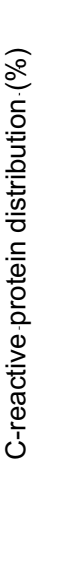

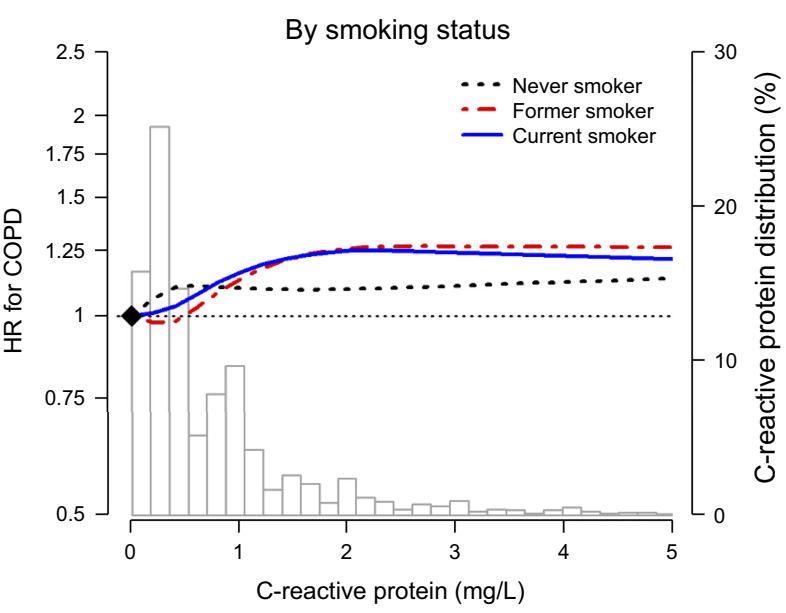

Figure 2 Hazard ratio for incident COPD by CRP levels at baseline. (A) represents overall hazard ratio and (B) represents hazard ratio by smoking status. Curves represent adjusted hazard ratios (solid lines) and their 95\% confidence intervals (dashed lines) based on restricted cubic splines for CRP with knots at the 5th, 35th, 65th, and 95th percentiles of their sample distributions. The reference values (diamond dots) were set at the 10th percentile of the distributions (corresponding to $0.1 \mathrm{mg} / \mathrm{L}$ ). Models were adjusted for age, sex, center, body mass index, smoking status, physical activity, alcohol consumption. Bars represent the frequency distribution of CRP.

Abbreviations: COPD, chronic obstructive pulmonary disease; CRP, C-reactive protein; HR, hazard ratio.

were lower in never smokers, but increased in former and current smokers, which supports the "spills over" theory in the development of COPD.

Our subgroup analysis revealed that CRP levels were not associated with the risk of COPD in never smokers, which suggests that risk factors other than smoking may be associated with the development of COPD. In particular, gender-related difference remains controversial, and little is known about the relationships among sex, CRP, and never-smoker COPD. In this study, the $76.5 \%$ of never smokers were female, and the hazard ratio for COPD in women is stronger than in never smokers, (1.17 vs 1.08), indicating that the lower risk for COPD in never smokers are not due to female sex. Moreover, in the subgroup analysis, the hazard ratio for women and men were similar, and the interactions by sex and smoking status were not statistically significant. An estimated $25-45 \%$ of patients with COPD have never smoked. ${ }^{32}$ Although genetic factors, outdoor air pollution, environmental smoke exposure, biomass smoke, and occupational exposure are all possible contributing factors for COPD in non-smokers, ${ }^{33}$ their assessment was not included in the present study. Thus, the origin or nature of systemic inflammation among the non-smoking subjects with COPD in this study could not be clearly determined. More investigations are required to verify the contribution of each risk factor to the development of COPD in order to better understand COPD in nonsmokers.
We found that those who developed COPD during follow-up had higher baseline $\mathrm{FVC}$, similar $\mathrm{FEV}_{1}$, and lower $\mathrm{FEV}_{1} / \mathrm{FVC}$ ratio compared with those participants without developed COPD. Since the volume of adult female is smaller than that of male, one of the possible reasons for higher baseline FVC in participants who developed COPD compared with those without COPD is sex difference. A total of $69.6 \%$ of participants in the COPD group were male, which is higher than those in the no COPD group (57.3\%). In addition, even though we cannot precisely determine the cut-off threshold, this data suggest that participants with reduced $\mathrm{FEV}_{1} / \mathrm{FVC}$ even within the normal value should be carefully followed-up for the development of COPD.

Diabetes is often associated with impaired lung function, but in this study, participants with diabetes were not associated with the risk of incident COPD. One of the explanations is that impaired lung function in those with diabetes is not consistent. A meta-analysis performed in participants with diabetes reported restrictive disease pattern rather than obstructive pattern seen in COPD. ${ }^{34}$ Moreover, other risk factors including age, smoking status, obesity, life style modification, comorbidity, and effect of anti-diabetic medication can affect this relationship. Further studies are necessary for a better understanding of the potential links between diabetes and COPD.

The strengths of the present study compared to those of previous studies are its large sample size and the use of 


\section{Subgroup}

Age

$<50(\mathrm{~N}=48,253)$

$\geq 50(\mathrm{~N}=15,007)$

$p$-value

Sex

Women $(\mathrm{N}=24,417)$

Men $(\mathrm{N}=38,843)$

$p$-value

\section{Smoking}

Never $(N=28,989)$

Former $(\mathrm{N}=18,392)$

Current $(N=15,879)$

$p$-value

\section{Alcohol drinking}

None $(N=19,528)$

Moderate $(\mathrm{N}=34,949)$

Heavy $(N=8,783)$

$p$-value

Physical activity

None $(N=30,974)$

Active $(N=32,286)$

$p$-value

BMI

$<25(\mathrm{~N}=41,692)$

$\geq 25(\mathrm{~N}=21,568)$

$p$-value

$1.22(1.09,1.37)$
$1.26(1.08,1.47)$
0.94

$1.17(0.95,1.45)$

$1.25(1.13,1.38)$

0.25

$1.08(0.90,1.30)$

$1.29(1.11,1.49)$

$1.25(1.08,1.45)$

0.14

$1.18(0.99,1.42)$

$1.24(1.10,1.39)$

1.27 (1.02, 1.59)

0.48

$1.19(1.03,1.36)$

$1.27(1.12,1.43)$

0.78

$1.25(1.12,1.39)$

$1.20(1.02,1.42)$

0.97

\section{Hypertension}

$$
\begin{aligned}
& \text { No }(\mathrm{N}=49,345) \\
& \text { Yes }(\mathrm{N}=13,915) \\
& p \text {-value }
\end{aligned}
$$

$1.22(1.10,1.36)$

$1.25(1.05,1.49)$

0.96

\section{Diabetes}

No $(\mathrm{N}=59,465)$

$1.24(1.13,1.37)$

Yes $(N=3,795)$

$1.24(0.85,1.79)$

$p$-value

0.54

Overall

\section{HR for COPD $(95 \% \mathrm{Cl})$}

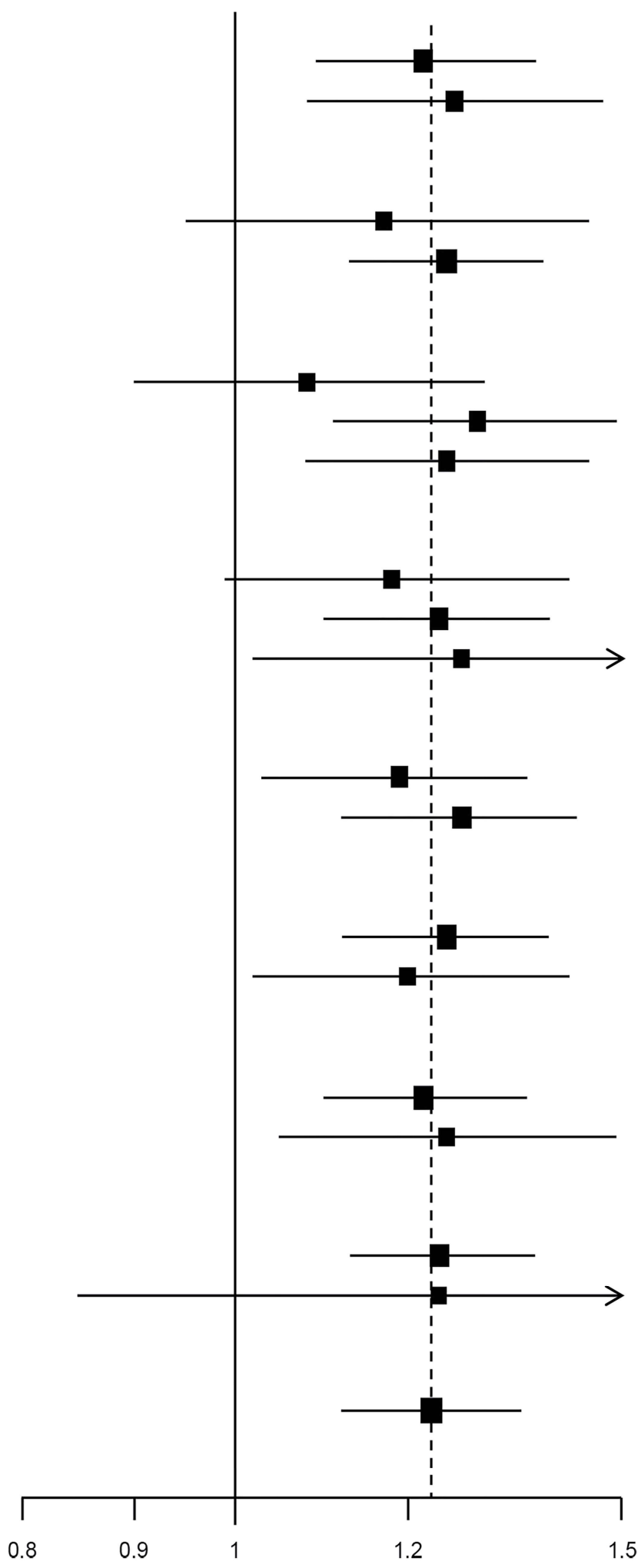

Figure 3 Associations between CRP (90th vs 10th percentile) and COPD by pre-specified subgroups. Models were adjusted for age, sex, center, smoking status, physical activity, alcohol consumption, and BMI.

Abbreviations: BMI, body mass index; COPD, chronic obstructive pulmonary disease; CRP, C-reactive protein; HR, hazard ratio. 
high-quality procedures. However, our study had several limitations. First, the presence of asthma at baseline was excluded only by questionnaire. Second, since we did not measure other airway inflammatory biomarkers, we could not establish the mechanism underlying the association between elevated CRP levels and the development of COPD. A longitudinal study investigating a combination of biomarkers and incident COPD should be performed. Finally, further research is needed to determine whether treatment of systemic inflammation is associated with prevention of COPD or favorable long-term clinical outcomes, such as decreased morbidity and mortality.

\section{Conclusion}

Our findings showed that higher baseline hsCRP is associated with an increased risk to develop COPD in ever smokers but not in never smokers. These data suggest the role of systemic inflammation in the development of COPD by smoking status.

\section{Acknowledgment}

This study did not receive external funding.

\section{Disclosure}

The authors report no conflicts of interest in this work.

\section{References}

1. Tkac J, Man SF, Sin DD. Systemic consequences of COPD. Ther Adv Respir Dis. 2007;1(1):47-59. doi:10.1177/1753465807082374

2. Mannino DM, Buist AS. Global burden of COPD: risk factors, prevalence, and future trends. Lancet. 2007;370(9589):765-773. doi:10.1016/S0140-6736(07)61380-4

3. MacNee W. Pathogenesis of chronic obstructive pulmonary disease. Proc Am Thorac Soc. 2005;2(4):258-266; discussion 290-251. doi:10.1513/pats.200504-045SR

4. Gan WQ, Man SF, Senthilselvan A, Sin DD. Association between chronic obstructive pulmonary disease and systemic inflammation: a systematic review and a meta-analysis. Thorax. 2004;59(7):574-580. doi:10.1136/thx.2003.019588

5. Agusti AG, Noguera A, Sauleda J, Sala E, Pons J, Busquets X. Systemic effects of chronic obstructive pulmonary disease. Eur Respir J. 2003;21(2):347-360.

6. Pinto-Plata VM, Mullerova H, Toso JF, et al. C-reactive protein in patients with COPD, control smokers and non-smokers. Thorax. 2006;61(1):23-28. doi:10.1136/thx.2005.042200

7. Fabbri LM, Rabe KF. From COPD to chronic systemic inflammatory syndrome? Lancet. 2007;370(9589):797-799. doi:10.1016/S01406736(07)61383-X

8. Garcia-Rio F, Miravitlles M, Soriano JB, et al. Systemic inflammation in chronic obstructive pulmonary disease: a population-based study. Respir Res. 2010;11:63. doi:10.1186/1465-9921-11-62

9. Sin DD, Anthonisen NR, Soriano JB, Agusti AG. Mortality in COPD: role of comorbidities. Eur Respir J. 2006;28(6):1245-1257. doi:10.1183/09031936.00133805
10. Eagan TM, Ueland T, Wagner PD, et al. Systemic inflammatory markers in COPD: results from the Bergen COPD Cohort study. Eur Respir J. 2010;35(3):540-548. doi:10.1183/09031936.00088209

11. Dahl M, Vestbo J, Lange P, Bojesen SE, Tybjaerg-Hansen A, Nordestgaard BG. C-reactive protein as a predictor of prognosis in chronic obstructive pulmonary disease. Am J Respir Crit Care Med. 2007;175(3):250-255. doi:10.1164/rccm.200605-713OC

12. Shaaban R, Kony S, Driss F, et al. Change in C-reactive protein levels and FEV1 decline: a longitudinal population-based study. Respir Med. 2006;100(12):2112-2120. doi:10.1016/j.rmed.2006. 03.027

13. Hancox RJ, Poulton R, Greene JM, et al. Systemic inflammation and lung function in young adults. Thorax. 2007;62(12):1064-1068. doi: $10.1136 /$ thx.2006.076877

14. van Durme YM, Verhamme KM, Aarnoudse AJ, et al. C-reactive protein levels, haplotypes, and the risk of incident chronic obstructive pulmonary disease. Am J Respir Crit Care Med. 2009;179(5):375382. doi: $10.1164 / \mathrm{rccm} .200810-1540 \mathrm{OC}$

15. Dahl M, Vestbo J, Zacho J, Lange P, Tybjaerg-Hansen A, Nordestgaard BG. C reactive protein and chronic obstructive pulmonary disease: a Mendelian randomisation approach. Thorax. 2011;66(3):197-204. doi:10.1136/thx.2009.131193

16. Fogarty AW, Jones S, Britton JR, Lewis SA, McKeever TM. Systemic inflammation and decline in lung function in a general population: a prospective study. Thorax. 2007;62(6):515-520. doi:10.1136/thx.2006.066969

17. Jiang R, Burke GL, Enright PL, et al. Inflammatory markers and longitudinal lung function decline in the elderly. Am J Epidemiol. 2008;168(6):602-610. doi:10.1093/aje/kwn174

18. Chang Y, Ryu S, Choi Y, et al. Metabolically healthy obesity and development of chronic kidney disease: a Cohort study. Ann Intern Med. 2016;164(5):305-312. doi:10.7326/M15-1323

19. Standardization of spirometry, 1994 update. American thoracic society. Am J Respir Crit Care Med. 1995;152(3):1107-1136. doi:10.1164/ajrccm.152.3.7663792

20. Royston P, Parmar MK. Flexible parametric proportional-hazards and proportional-odds models for censored survival data, with application to prognostic modelling and estimation of treatment effects. Stat Med. 2002;21(15):2175-2197. doi:10.1002/sim.1203

21. de Torres JP, Cordoba-Lanus E, Lopez-Aguilar C, et al. C-reactive protein levels and clinically important predictive outcomes in stable COPD patients. Eur Respir J. 2006;27(5):902-907. doi:10.1183/ 09031936.06.00109605

22. Zhang Y, Bunjhoo H, Xiong W, Xu Y, Yang D. Association between $\mathrm{C}$-reactive protein concentration and chronic obstructive pulmonary disease: a systematic review and meta-analysis. J Int Med Res. 2012;40(5):1629-1635. doi:10.1177/030006051204000501

23. Rasmussen F, Mikkelsen D, Hancox RJ, et al. High-sensitive Creactive protein is associated with reduced lung function in young adults. Eur Respir J. 2009;33(2):382-388. doi:10.1183/090319 36.00040708

24. Kalhan R, Tran BT, Colangelo LA, et al. Systemic inflammation in young adults is associated with abnormal lung function in middle age. PLoS One. 2010;5(7):e11431. doi:10.1371/journal.pone.0011431

25. Hersh CP, Miller DT, Kwiatkowski DJ, Silverman EK. Genetic determinants of C-reactive protein in COPD. Eur Respir J. 2006;28 (6):1156-1162. doi:10.1183/09031936.00147805

26. Breyer MK, Spruit MA, Celis AP, et al. Highly elevated C-reactive protein levels in obese patients with COPD: a fat chance? Clin Nutr. 2009;28(6):642-647. doi:10.1016/j.clnu.2009.05.005

27. Woloshin S, Schwartz LM. Distribution of C-reactive protein values in the United States. $N$ Engl J Med. 2005;352(15):1611-1613. doi:10.1056/NEJM200504143521525

28. Agusti A. Systemic effects of chronic obstructive pulmonary disease: what we know and what we don't know (but should). Proc Am Thorac Soc. 2007;4(7):522-525. doi:10.1513/pats.200701-004FM 
29. Barnes PJ, Celli BR. Systemic manifestations and comorbidities of COPD Eur Respir J. 2009;33(5):1165-1185. doi:10.1183/09031936.00128008

30. Hansson GK. Inflammation, atherosclerosis, and coronary artery disease. N Engl J Med. 2005;352(16):1685-1695. doi:10.1056/NEJMra043430

31. Sevenoaks MJ, Stockley RA. Chronic obstructive pulmonary disease, inflammation and co-morbidity-a common inflammatory phenotype? Respir Res. 2006;7:70. doi:10.1186/1465-9921-7-70

32. Salvi SS, Barnes PJ. Chronic obstructive pulmonary disease in nonsmokers. Lancet. 2009;374(9691):733-743. doi:10.1016/S0140-6736 (09)61303-9
33. Eisner MD, Anthonisen N, Coultas D, et al. An official American Thoracic Society public policy statement: novel risk factors and the global burden of chronic obstructive pulmonary disease. Am J Respir Crit Care Med. 2010;182(5):693-718. doi:10.1164/rccm.200811-1757ST

34. van Den Borst B, Gosker HR, Zeegers MP, Schols AM. Pulmonary function in diabetes: a metaanalysis. Chest. 2010;138(2):393-406. doi:10.1378/chest.09-2622 


\section{Supplementary material}

Table SI Baseline characteristics of study participants by incident COPD status

\begin{tabular}{|c|c|c|c|}
\hline Characteristic & No COPD during follow-up & COPD during follow-up & $P$-value \\
\hline $\mathrm{N}$ & 59,001 & 4,259 & \\
\hline Age (years) & $46.6(6.2)$ & $48.7(7.8)$ & $<0.001$ \\
\hline C-reactive protein $(\mathrm{mg} / \mathrm{L})^{\mathrm{a}}$ & $0.5(0.2-1.0)$ & $0.6(0.2-1.1)$ & $<0.001$ \\
\hline $\mathrm{FEV}_{1}$ & $3.3(0.8)$ & $3.3(0.8)$ & 0.45 \\
\hline FVC & $3.9(0.9)$ & $4.1(0.9)$ & $<0.001$ \\
\hline $\mathrm{FEV}_{\mathrm{l}} / \mathrm{FVC}$ & $84.5(6.4)$ & $80.2(7.3)$ & $<0.001$ \\
\hline Male & $35,339(59.9)$ & $3,504(82.3)$ & $<0.001$ \\
\hline Study center & & & $<0.001$ \\
\hline Seoul & $47,603(80.7)$ & $3,359(78.9)$ & \\
\hline Suwon & II,398 (19.3) & $900(21.1)$ & \\
\hline Body mass index $\left(\mathrm{kg} / \mathrm{m}^{2}\right)$ & $23.9(2.9)$ & $24.0(2.7)$ & 0.16 \\
\hline Total cholesterol (mg/dL) & $201.6(34.8)$ & $202.7(34.3)$ & 0.05 \\
\hline HDL cholesterol (mg/dL) & $55.7(13.5)$ & $54.1(12.6)$ & $<0.001$ \\
\hline Triglycerides $(\mathrm{mg} / \mathrm{dL})^{\mathrm{a}}$ & $110.0(77.0-162.0)$ & $120.0(86.0-173.0)$ & $<0.001$ \\
\hline Smoking & & & $<0.001$ \\
\hline Never & $27,964(47.4)$ & $\mathrm{I}, 025(24.1)$ & \\
\hline Former & $16,828(28.5)$ & $\mathrm{I}, 564(36.7)$ & \\
\hline Current & $14,209(24.1)$ & $1,670(39.2)$ & \\
\hline Alcohol & & & $<0.001$ \\
\hline None & $18,528(3 \mid .4)$ & $1,000(23.5)$ & \\
\hline Moderate & $32,460(55.0)$ & $2,489(58.4)$ & \\
\hline Severe & $8,013(13.6)$ & $770(18.1)$ & \\
\hline Vigorous exercise (times/week) & & & 0.005 \\
\hline 0 & $29,105(49.3)$ & $1,869(43.9)$ & \\
\hline $\mathrm{I}-3$ & $19,895(33.7)$ & $1,576(37.0)$ & \\
\hline$>3$ & $10,001(17.0)$ & $814(19.1)$ & \\
\hline Fasting glucose $(\mathrm{mg} / \mathrm{dL})$ & $97.3(18.3)$ & $97.3(17.0)$ & 0.86 \\
\hline Diabetes & $3,523(6.0)$ & $272(6.4)$ & 0.27 \\
\hline Systolic blood pressure $(\mathrm{mmHg})$ & II $14.6(14.6)$ & II7.I (14.5) & $<0.001$ \\
\hline Diastolic blood pressure $(\mathrm{mmHg})$ & $74.8(10.4)$ & $76.5(10.1)$ & $<0.001$ \\
\hline Hypertension & $12,760(2 \mid .6)$ & $\mathrm{I}, 155(27.1)$ & $<0.001$ \\
\hline
\end{tabular}

Notes: Values are expressed as mean (standard deviation) or number (\%). ${ }^{\text {Madian }}$ (interquartile range).

Abbreviations: COPD, chronic obstructive pulmonary disease; FEV , forced expiratory volume in I second; FVC, forced vital capacity; HDL, high-density lipoprotein.

International Journal of Chronic Obstructive Pulmonary Disease

\section{Dovepress}

\section{Publish your work in this journal}

The International Journal of COPD is an international, peer-reviewed journal of therapeutics and pharmacology focusing on concise rapid reporting of clinical studies and reviews in COPD. Special focus is given to the pathophysiological processes underlying the disease, intervention programs, patient focused education, and self management protocols. This journal is indexed on PubMed Central, MedLine and CAS. The manuscript management system is completely online and includes a very quick and fair peer-review system, which is all easy to use. Visit http://www.dovepress.com/testimonials.php to read real quotes from published authors. 